Trivent Publishing

(C) The Authors, 2018

Available online at http:/ / trivent-publishing.eu/

Series: Applied Ethics: From Bioethics to Environmental Ethics

\title{
Cultural and Ethical Aspects of Social Desirability in Psychological Research
}

\author{
Maria Ancuta Gurza \\ Alexandru Ioan Cuza University of Iasi, Romania
}

Abstract: This study is part of an exploratory work on the child-parent relationship from the perspective of attachment theory and parenting styles. In the context of an increased interest in psychological research on foster parenting, the implications of social desirability for psychological assessment are discussed. This chapter aims to answer the following questions: what is the difference in social desirability between biological and foster parents? What is the effect size of the different correlations between social desirability and other psychological characteristics in the two groups of parents? The research sample was formed of 216 dyads, of which 108 parent-biological child and 108 foster parent-foster child. The ethical aspects of clinical research and the cultural influences associated with social desirability are discussed.

Keywords: ethics of research; social desirability; professional foster care; childparent relationship; attachment; parenting.

This is an Open Access article distributed in accordance with the Creative Commons Attribution Non Commercial (CC-BY-NC-ND 4.0) license, which permits others to copy or share the article, provided original work is properly cited and that this is not done for commercial purposes. Users may not remix, transform, or build upon the material and may not distribute the modified material (bttp:/ / creativecommons.org/licenses/by-nc/4.0/) 


\title{
Cultural and Ethical Aspects of Social Desirability in Psychological Research
}

\author{
Maria Ancuta Gurza
}

\section{Introduction}

People adopt proactive attitudes in social situations and structure their environment by placing themselves in pleasant situations and in circumstances which ensure their well-being [1]. Some researchers consider that the core of social life is the control of information on one's own identity, activities carried out together with others, and interpersonal relationships [2].

Concepts of social psychology such as impression regulation, impression management, and self-presentation refer the control (intentional or not) of the self-information that people present to others. They do not randomly communicate information on their own person; the situation they are in and the way they relate to it influences how they choose to present information. There is still debate in the literature about the purpose of impression management between those who argue that such behaviour occurs in specific situations and has negative connotations and others who argue that such social behavioural patterns are universal.

These aspects of impression management are especially important when considering evaluating attitudes and behaviours. In this context, parenting, attachment, and couple satisfaction are central elements in life and their assessment is influenced by cultural factors, as well as the context and the way in which the information is requested [3]. Moreover, any intervention in this area can be perceived negatively [4].

Traditional cultural characteristics specific to Romanian society present a challenge to researchers seeking proceeures to access family constructs. Furthermore, it is relevant to take in consideration the respondents' degree of social desirability in order to accurately interpret the data obtained.

Child rearing is a complex activity, defined as a set of normal variations of parental expectations of child control and socialization [5]. Baumrind's model [6] highlights three parenting styles based on two dimensions: parental responsiveness related to parental involvement in relation to children, and parental demandingnesss related to the active role that parents play in promoting compliance with social norms and conventions [7]. 
Parenting styles, generally speaking, are a function of parental attitudes, beliefs and behaviours, and as some authors [8] argue, they reflect both the parents' goals for their children's socialization and the emotional climate where the parenting practices are implemented [9]. Thus, an authoritative style is often associated with positive effects on the child (e.g. emotional stability, good coping mechanisms, a good level of satisfaction of one's own life) and involves a high level of parental warmth and responsiveness along with a high level of parental control and realistic requirements, having great expectations for their children. These parents provide children with orientation and guidance, but in the context of a warm and loving relationship [7]. Authoritarian style (low responsiveness combined with a high level of unrealistic demands) is characterized by a high expectation of child obedience in the context of a relationship with low affection or a distant parental relationship. This style has been associated with low academic performance and depressive symptoms. In terms of academic performance, studies [10] show that in certain conditions, this style is associated with high academic performance. Parents who practice a permissive parental style, characterized by increased responsiveness and low realistic expectations, give little orientation and guidance to children, and their children are inclined to show low selfcontrol, low self-esteem, and aggression.

The practice of a given parental style was investigated in relation to the personality of the parent, their socio-economic level, cultural affiliation, marital satisfaction, etc. [11]. Studies show that practicing a positive parental style is accompanied by a certain balance in terms of marital satisfaction. Along with this, the insecurity of adult attachment becomes an important aspect of promoting good dyadic relationships. The attachment-related anxiety dimension is defined as adults' feelings, thoughts, and behaviours reflecting their levels of anxiety to the extent to which they feel loved by their partners, and perceive their partners as responsive to their needs. The attachmentrelated avoidance dimension is defined as adults' thoughts, feelings, and behaviours reflecting their levels of discomfort with closeness and dependency on others in their close relationships [12].

The objectives of the present study were: 1) to identify the difference in social desirability between biological and foster parents; 2) to measure the levels of association between social desirability and the anxiety and avoidance dimensions of attachment, as well as the marital satisfaction in the two groups of parents; 3) to study whether the parental style perceived by the parent as dominant is differently associated with social desirability in the two types of dyads; 4) to investigate whether there are significant differences between the correlation coefficients obtained for the two groups of parents.

The answer to these questions is relevant for understanding the extent to which social cognitions are specific to certain social groups or can be 
generalized to these groups [13]. This study aims to provide new perspectives into the social desirability of respondents from different social groups,. This is significant for clinical evaluations and interventions in the child-parent dyad, considering the tendency to desirable responses from parents. It is also important to recognise that what counts as a socially-desirable response is closely related to the cultural aspects of research constructs [13] and mirrors how members of a society recognize and adhere to perceived cultural norms [14].

Foster families exist in all cultures as the most effective service for children separated from their biological parents. Compared with biological families, social families are more flexible and more open to those who seek to evaluate aspects of family relationships because they are used to being evaluated by Child Welfare Systems. Kim et al [11] highlight the paradox that these families, although they from a constituent part of the child welfare system in every country, are expected to provide care to children at a standard similar to that provided by the natural family. Social parents go through a selection process, initial and regular training, and have continuous professional supervision in accordance with the law. In other words, these families behave according to professional standards, supported and controlled by the representatives of the protection system.

Foster families are therefore exposed to the intrusion of professionals, and from this point of view are highly different from the biological families whose borders protect their privacy and do not reveal themselves as much to nonfamily. Working as an interface between the Child Welfare System and the child, the foster family has the subtle task of preserving its unity and its boundaries with the world, like any other family. A placement family therefore has to navigate between the requirements of family integrity and the requirements of healthy child care.

\section{Method}

Data collection was carried out through self-reporting within group assessment sessions (four with professional foster carers and four with biological parents). The data was collected in the presence of case managers in the groups of foster parents and of school teachers in the groups of biological parents.

\section{Participants}

The participants in the research study included 216 parent-child dyads, of which half $(\mathrm{n}=108)$ were biological families, and half $(\mathrm{n}=108)$ were social families. Five $(9 \%)$ involved couples of social parents and $98(91 \%)$ single parents, of which $82(84 \%)$ were social mothers and $26(16 \%)$ foster care 
fathers. These foster families lived in the Timis County (Romania), 41(37,9\%) in rural areas and $67(62 \%)$ in the city of Timisoara.

With respect to parental levels of education, 11 mothers and two fathers $(\mathrm{N}=13 ; 12 \%)$ had completed secondary school (eight school classes), 19 mothers and six fathers $(\mathrm{N}=25 ; 23 \%)$ had finished vocational high school, 51 mothers and 10 fathers $(\mathrm{N}=61 ; 56.5 \%)$ had completed academic high school, and six mothers and three fathers $(\mathrm{N}=9 ; 8 \%)$ were university graduates. The foster parents were aged between 35 and $74(\mathrm{~m}=51.86$; st.d=8.39).

The general criterion for including these families in the study was to have at least one child in foster care for a minimum of one year. The sub-criteria for inclusion were the following:

- the child was covered by a protection order throughout the period of professional foster care;

- the children's age was between 10 and 17.

The exclusion criteria for the participants in the research were:

- children diagnosed with mental illness, mental retardation, or severe physical disability;

- the period spent by the child in foster was less than one year.

The 108 biological parent-child dyads were recruited in the same period within three schools, one in an urban area and two in rural areas, in two different counties of Romania. The recruitment of families was random, depending only on the willingness of the staff in the schools to be involved. Of the parents, $12(11 \%)$ were single parents (two divorced, four widowed, six mothers who have never married) and $96(88.8 \%)$ had complete families. No couples were included in the data collected. Regarding gender, the group includes four fathers $(3,7 \%)$ and 104 mothers $(96,3 \%)$. From an educational point of view, 18 parents $(16,6 \%)$ finished secondary school, 71 (65,7\%) completed high school, and 19 (17,5\%) were university graduates. All parents were Christian Orthodox. Their ages ranged between 28 and 59 ( $\mathrm{m}=41.18$; st.d.=6.44).

\section{Procedure}

The data was collected considering the attachment and parental style for children raised in foster families compared to those raised in biological families.

The foster care families involved in the study were recruited by the Timis DGASPC $^{1}$ in response to the researcher's written request. Foster parents were

\footnotetext{
1 The county administrative structure known as the General Social Work and Child Protection Authority.
} 
invited to the DGASPC headquarters, where between December 2016 and February 2017, groups of 20-25 parents, overseen by the case manager and the researcher, completed self-report questionnaires. The sample consisted of 82 foster mothers $(76 \%)$ and 26 foster fathers (24\%), all registered at DGASPC. As this research was concerned with parent-child dyads, it was carried out in accordance to the ethical research principles of the Ethics Code of Psychology Research and the Society for Research in Child Development (srcd.org). Both biological and foster parents agreed to participate in the research on the basis of informed consent. The children's questionnaires were completed at home and returned to case managers and then to the researcher.

Six classes were recruited from the three schools involved in the research. In the two rural schools, the questionnaires were applied to parents and children $(\mathrm{N}=68 ; 62.9 \%)$ in the classroom, with the class supervisor and the researcher present. In the urban school, the 40 children and their parents (37\%) completed the questionnaires at home and then handed them in to the class supervisor.

\section{Measurements}

Although the research used a larger number of measurements to collect data, the following measurements, which are the subject of the present study, are described below.

DECAS Personality Inventory - The "Big-Five" personality profile [15] was employed in order to obtain an adult personality profile [16]. This study used the recorded results only on the social desirability scale, the items of this scale being made and selected taking into consideration the correlations with the two social desirability scales: Marlowe - Crowne Scale and BFQ-2 Scale [15].

The Dyadic Adjustment Scale (DAS) Marriage Satisfaction Questionnaire created by Spanier (1976). The scale contains 32 items divided into 4 subscales, measuring the dyadic consensus (the extent to which the partners agree on important aspects), the cohesion of the couple (the extent to which the partners engage in similar activities), couple fulfilment (the degree of satisfaction in the relationship), and expression of affectivity (sexual and physical affection within the relationship). The internal consistency of the instrument on each subscale is between 0.73 and 0.96 , which is a high coefficient. In this research, the Alpha Crombach coefficient of the scale was 0.64 with the following coefficients on each sub-scale: 0.53 for couple fulfilment; 0.67 for the degree of cohesion; 0.40 for consensus; 0.56 for expression of affectivity.

The Parental Authority Questionnaire - PAQ developed by Buri [17] was translated and used in Romanian in an unpublished dissertation, which reported an Alpha Crombach of 0.74 [18]. The assessment forms for parents 
identify parental practices as reported by parents. When the instrument is used in Romania, the internal consistency of the scale for children is Alpha Cronbach $=0.72$, and for the group of parents, Alpha Cronbach $=0.85$. The assessment forms for children identify parental practices as reported by children. The scale measured the three parental styles described by Baumrind (1967) [5]: permissive, authoritarian, and authoritative.

The Experiences in Close Relationships-Revised (ECR-R), [19] was used to assess the dimension of adult attachment. This instrument was adapted to the Romanian population [20] and used to investigate the attachment of adults based on two dimensions: anxiety and avoidance [12]. For both the English and the Romanian-adapted versions, the subscales show very high internal consistency (in the English version, Alpha Cronbach for Anxiety $=0.91$, and for Avoidance $=0.94$, in the Romanian version, Alpha Cronbach for Anxiety $=0.85$, and Avoidance $=0.81$.

\section{Statistical analysis}

This study is a non-experimental one with a standard dyadic design. All statistical analyses were carried out using IBM SPSS Statistics version 20 (SPSS Inc.; Chicago, IL, USA). Descriptive statistics, comprising means, standard deviations, frequencies and percentages were performed to examine socio-demographic characteristics. All data were checked for normality on skewness and kurtosis measures. Information source differences in quantitative variables were tested using the independent sample $t$ test. Pearson's correlations were used to assess associations between variables. The analysis of the difference between two correlation coefficients (to assess whether they are genuinely different from each other) used the $\mathrm{q}$ indicator and $\Delta \mathrm{r}^{2}$ was used for the effect size. These indicators were obtained using PowerStaTim, Version 1.2.0.0.[20]. All significance tests were conducted on the $\alpha=0.05$ level and were two-tailed.

\section{Results}

Descriptive statistics. The means and standard deviations, for the Parental Authority Questionnaire-Revised (PAQ-R; Buri, 1991), ECR-R, Dyadic Adjustment Scale (Spanier, 1976) and Personality Inventory DECAS [16]are shown in Table 1. The responses to the Parental Authority QuestionnaireRevised range from 1 to 5 . In this sample, the Internal consistency for the PAQ-R $(a=0.78)$ was lower than the alpha of 0.82 reported in Buri [17] . The responses to the Experiences in Close Relationship Scale-Revised (ECR - R; Brennan, Clark, \& Shaver, 1998) range from 1 to 7, internal consistency for the ECR-R was $a=0.86$. The responses to the Dyadic Adjustment Scale range from 0 to 5. In this sample, the Internal consistency for the DAS was $a=0.65$. 
The responses to Social desirability range from 0 to 1 , Internal consistency for the DECAS Social Desirabiliy is reported as $a=0.69[16]$.

Table 1. Descriptive statistics for parent anxiety and the dimensions of attachment avoidance in romantic relationships, parental styles, and Dyadic Adjustment Scale dimensions within the biological and foster families

\begin{tabular}{|l|l|r|r|r|r|}
\hline & & \multicolumn{2}{|c|}{ Biological parents } & \multicolumn{2}{|c|}{ Foster parents } \\
\hline Variable & $N$ & \multicolumn{1}{|c|}{$M$} & \multicolumn{1}{c|}{$S D$} & \multicolumn{1}{c|}{$M$} & \multicolumn{1}{c|}{$S D$} \\
\hline Social desirability (DECAS) & 108 & 15.78 & 3.04 & 19.21 & 2.32 \\
\hline Permissive Style (PAQ-R) & 108 & 32.42 & 4.83 & 32.00 & 4.18 \\
\hline $\begin{array}{l}\text { Authoritarian Style (PAQ- } \\
\text { R) }\end{array}$ & 108 & 29.38 & 8.38 & 23.80 & 5.52 \\
\hline $\begin{array}{l}\text { Authoritative Style (PAQ- } \\
\text { R) }\end{array}$ & 108 & 40.93 & 3.48 & 41.78 & 3.75 \\
\hline Anxiety subscale (ECR-R) & 108 & 42.65 & 10.02 & 38.73 & 9.79 \\
\hline $\begin{array}{l}\text { Avoidance subscale (ECR- } \\
\text { R) }\end{array}$ & 108 & 43.22 & 16.17 & 31.55 & 10.77 \\
\hline Couple fulfilment (DAS) & 108 & 57.92 & 3.69 & 59.77 & 4.32 \\
\hline Dyadic consensus (DAS) & 108 & 34.48 & 3.34 & 35.76 & 3.34 \\
\hline Dyadic cohesion (DAS) & 108 & 18.78 & 3.34 & 19.87 & 3.50 \\
\hline Expression of affection (DAS) & 108 & 14.70 & 1.35 & 15.25 & 1.52 \\
\hline
\end{tabular}

\section{Major findings}

In order to investigate the differences between biological and foster parents, we applied the $t$ test for independent samples. The results obtained are illustrated in Table 2.

A significant difference can be seen in social desirability between biological and foster parents, as foster parents obtained significantly higher scores than biological parents [ $t(200.04)=-9.280]$. Furthermore, the magnitude of this correlation is very strong (Cohen's $\mathrm{d}=1.31$ ).

Table 2. The significance of parent social desirability differences in the two types of families (biological/social)

\begin{tabular}{|c|c|c|c|c|c|c|c|}
\hline & Family & $\mathrm{N}$ & Mean & $\begin{array}{c}\text { Std. } \\
\text { Deviation }\end{array}$ & $\mathrm{t}$ & $\mathrm{df}$ & $\mathrm{p}$ \\
\hline $\begin{array}{c}\text { Social } \\
\text { desirabi- } \\
\text { lity }\end{array}$ & $\begin{array}{c}\text { Biologi- } \\
\text { cal }\end{array}$ & 108 & 15.78 & 3.04 & -9.280 & 200.04 & $\mathbf{. 0 0 0}$ \\
\cline { 2 - 8 } & foster & 108 & 19.21 & 2.32 & & & \\
\hline
\end{tabular}


In order to identify the strength of association between social desirability, parental styles, the anxiety and avoidance of adult attachment in close relationships, as well as marital satisfaction, we used the Pearson correlation coefficient; Table 3 comparatively illustrates the significant associations found in the two types of families.

The social desirability of the biological parents in this study is negatively associated with the permissive style $[\mathrm{r}(108)=-0.269, \mathrm{p}<0.01]$ and with the authoritarian style, $[\mathrm{r}(108)=-0.293, \mathrm{p}<0.01]$. A high level of social desirability is also associated with a high level of avoidance in adult attachment, [r (108) $=$ $-0.344, \mathrm{p}<0.01]$. A positive correlation was found between social desirability and the dyadic cohesion of biological parents $[\mathrm{r}(108)=0.298, \mathrm{p}<0.05]$. These findings point to the fact that the biological parents who obtained high scores on the social desirability dimension tend to appreciate less permissive and less authoritarian parental styles. A high level of social desirability is also associated with a high avoidance of attachment in close relationships and high dyadic cohesion.

The social desirability of the foster parents is negatively associated with the authoritarian style, [r (108) $=-0.243, \mathrm{p}<0.05]$, and with the avoidance of adult attachment in romantic relationships, [ $\mathrm{r}(108)=-0.249, \mathrm{p}<0.05]$. In other words, the higher the social desirability level, the more they appreciate less authoritarian parenting styles and manifest higher avoidance in romantic relationships. This tendency to offer social desirable responses is accompanied by the tendency towards a rather authoritative parental style, $[\mathrm{r}(108)=0.246$, $\mathrm{p}<0.05$ ], while couple fulfillment is higher. [ $\mathrm{r}(108)=0.311, \mathrm{p}<.01]$.

As shown in Table 3, the two groups of parents are similar in their associations between social desirability and authoritarian style and between authoritarian style 0 and the avoidance dimension of adult attachment. There are some differences between the two groups of parents on the level of the other variables associated with social desirability.

Table 3. The signification of the correlations between social desirability and parental styles, attachment dimensions, couple satisfaction

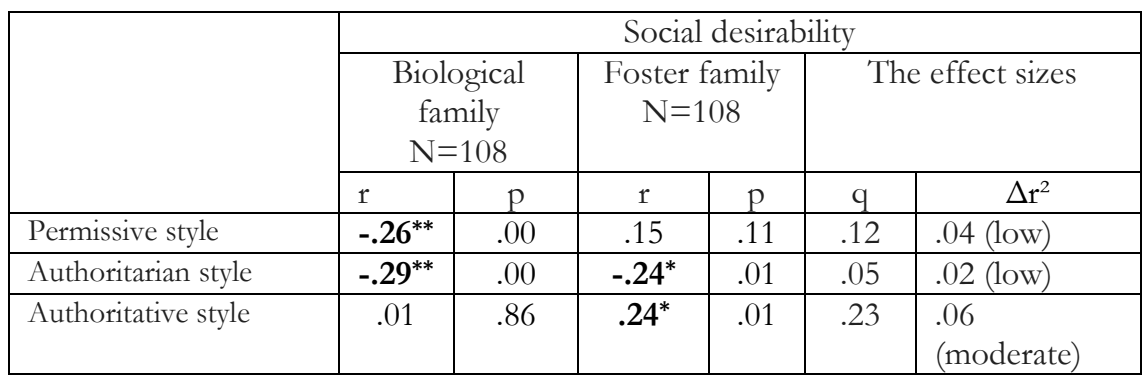


Cultural and Ethical Aspects of Social Desirability...

\begin{tabular}{|l|c|c|c|c|c|l|}
\hline $\begin{array}{l}\text { Anxious dimension of } \\
\text { attachment }\end{array}$ & -.15 & .11 & -.13 & .17 & & \\
\hline $\begin{array}{l}\text { Avoidance dimension } \\
\text { of attachment }\end{array}$ &.$- .34^{* *}$ & .00 & $-.24^{* *}$ & .00 & .10 & .05 (low) \\
\hline Couple fulfilment & .04 & .65 & $.33^{* *}$ & .00 & .30 & .11 (moderate) \\
\hline Dyadic consensus & .14 & .14 & -.08 & .37 & & \\
\hline Dyadic cohesion & $.29^{* *}$ & .00 & .06 & .50 & .24 & $\begin{array}{l}.08 \\
\text { (moderate) }\end{array}$ \\
\hline Expression of affection & .13 & .15 & $.19^{*}$ & .04 & & \\
\hline
\end{tabular}

$\mathrm{p}<.05^{*}, \mathrm{p}<.01^{* *}$

The question we sought to answer in this study was whether social desirability is a predictor of the positive appreciation of marital relationships and the parent-child relationships for biological parentsrather than for foster parents. So, we calculated a base indicator $\mathrm{q}$ and the effect size noted as $\Delta \mathrm{r}^{2}$, which represent the magnitude of the difference between the two $r^{2}$ coefficients obtained [15]. Table 3 shows that the effect size of the differences between the correlation coefficients are low and moderate.

Thereffore, regardless of their type of family, parents with a high level of social desirability have a tendency to appreciate less authoritarian and less permissive parental styles. Also, parents with a high level of attachment avoidance in romantic relationships tend to exhibit a high level of desirability.

The magnitude of the difference between the correlation coefficients was average on the level of the authoritative style and the two dimensions of marital satisfaction: dyadic cohesion and couple fulfilment. Thus, social parents who manifest a higher level of social desirability tend to appreciate more authoritative parental styles and show higher levels of couple fulfilment. Biological parents who obtained higher scores on the social desirability scale tend to have a higher appreciation of dyadic cohesion.

\section{Discussion}

The main purpose of this study was to identify the differences in the social desirability between biological and foster parents in order to identify the extent to which that dimension can be considered a good predictor of positive appreciation of the marital relationship and parent - child relationship.

We considered that a positive appreciation of the couple's relationship is manifested by high scores in the dimensions of marital satisfaction and a low level of anxiety and attachment avoidance in romantic relationships. The positive appreciation of the parent-child relationship was operationalized by the extent to which the parent considered that he/she practiced a parental 
responsiveness (permissive and authoritative) style rather than a parental demandingness (authoritarian) style [5].

We expected that foster parents would obtain lower scores on the social desirability scale because of their frequent contact with the Child Welfare System compared to the biological parents who are only ocassionally asked by the school to evaluate their family relationships.

The wide-ranging framework of impression management underlines the fact that, in the self-assessments of attitudes or behaviours, individuals can claim desirable attributes not only directly, by presenting information on their own qualities, but also indirectly, by presenting information on the qualities of others. Our findings demonstrate these theoretical observations in the correlations shown between the two dimensions of Dyadic Adjustment Scale (dyadic cohesion and couple fulfilment) and social desirability.

Social desirability becomes important for discussing the precision of attitude measurement. Attitudes become acute when targeting differently validated cultural and social behaviours. In these two groups of parents, both the assessment constructs (attitudinal/emotional), the way in which the study was carried out (group assessment) and the (institutional) framework in which it took place, and given the specific cultural context of the research, as well as the limitations of its proper ethical constraints, these findings need to be interpreted with an appropriate level of caution.

However, such considerations do require us to discuss concepts such as self-presentation, desirable identity, and social desirability. Thus, regardless of the type of family they belong to, parents who appreciate their parental style as authoritarian tend to provide socially-desirable responses. They also show a high level of attachment avoidance in romantic relationships, which, according to attachment theory, shows a lack of affective involvement in their relationship with the child[21].

Some authors [9] consider that for good child development in a foster family, it is necessary to meet the conditions considered in the stages of recruitment, the monitoring and evaluation of parents: the desire of the family members to care for a child and their motivation; good parental competence including quality of child care, promotion of children's independence, nonpunitive discipline and the quality of specific treatments; emotional security of parents.

These dimensions are periodically evaluated by case managers and psychologists who monitor the foster family. This way, the support provided by child welfare workers to foster parents in terms of how to interact with the child, but also aspects of the couple relationship, lead to a higher likelihood that they will provide answers presenting an enhanced level of social desirability in the context of a group evaluation. In turn, biological parents are less well-informed about these aspects of family relationships, and this may be 
an explanation of their lower desirability in responding. This observation is also supported by the differences in the relationships between social desirability and the dimensions of marital satisfaction appreciated by the two types of parents.

The differences between the two parental groups regarding couple fulfilment and dyadic cohesion support the idea that desirable answers were selected by the foster parents, in the sense that their social desirability is associated with the emotional stability dimension, an aspect directly targeted during the evaluation for child placement in a foster family. Whereas in the group of biological parents, the tendency to desirability responses is associated with the answers given on the level of dyadic cohesion, a more pragmatic aspect of the couple relationship, referring to commitments and involvement in collective activities.

The results of this study are important both for identifying cultural influences on family life and for emphasizing aspects of professional ethics in relation to the three actors: children, foster parents and the Child Welfare System. Although research on foster parents in Romania is still at the beginning, this study highlights important aspects and limitations which must be considered for the accurate interpretation of findings.

Some limitations of the study need to be considered. Firstly, the procedure of recruitment based on the goodwill of institutional staff requires caution caution when generalizing the results. Also, as a comparative study, the results cannot be used to infer causal relationships between the variables. The results of this study emphasize once again the importance of discussing social desirability in the cultural context of both family and institutional relationships, and it is possible to assert that professional foster parents incline to manifest a certain degree of institutionalised behaviour. For a clearer image of the associations of these constructs, as well as for a study of possible causal conclusions, we propose the elaboration of more complex methodological studies involving this particular social group. The aspects discussed here highlight important ethical and cultural factors which could be useful in clinical intervention and practice involving parent-child dyads regardless of whether they are biological or formed through a fostering relationship.

\section{References}

[1] S. Boncu. Psibologie si Societate [Psychology and Society]. Iasi: Editura EEOTA, 1999.

[2] E. Goffman. Behavior in Public Places. New York: The Free Press, 1963.

[3] M. Kemmelmeier. "Cultural differences in survey responding: Issues and insights in the study of response biases." International Journal of Psychology 51(6) (2016): 439-444, doi: 10.1002/ijop.12386 
[4] M. Roth, C. Voicu, A. Dávid-Kacsó, I. Antal, A. Muntean, S. Bumbulu, C. Baciu. "Asking for parental consent in research on exposure of children to violence." Revista de cercetare si interventie sociala 42 (2013): 85-100.

[5] Baumrind, D. "Child care practices anteceding three patterns of preschool Behavior." Genetic Psychology Monographs 75(1) (1967): 43-88.

[6] C. H. Hart, L.D Newell, S. G. Olsen, John O. "Parenting skills and socialcommunicative competence in childhood." 753-797. In Handbook of communication and social interaction skills; ed. Burleson, B. R. Mahwah, NJ: Lawrence Erlbaum Associates Publishers, 2003.

[7] Akhter, N., Hanif, R., Tariq, N., \& Atta, M. "Parenting styles as predictors of externalizing and internalizing behavior problems among children." Pakistan Journal of Psychological Research 26(1) (2011): 23-41. Available at https://search.proquest.com/docview/920830272?accountid=136549.

[8] N. Darling, L.Steinberg. "Parenting style as context: An integrative model."Psychol Bull 113 (1993): 487-496.

[9] T. G.Power, E. F. C. Sleddens, J. Berge, , L. Connell, B. Govig, E. Hennessy, S. M St George. "Contemporary research on parenting: Conceptual, methodological, and translational issues." Childhood Obesity 9: 87-94. doi: 10.1089/chi.2013.0038.

[10] Lola, B., Shrinidhi, I. "Parenting styles: the impact on student achievement." Marriage Fam. Rev. 43 (2008): 14-38.

[11] J. Kim , J. L. Shawna, C. A. Taylor, and N. Guterman. "Dyadic Profiles of Parental Disciplinary Behavior and Links With Parenting Context." Child Maltreatment 19(2) (2014): 79-91, doi: 10.1177/1077559514532009

[12] K. A.Brennan, L. C. Clark, \& , P. R. Shaver. "Self-report measurement in adult attachment: an integrative overview". In Attachment theory and close relationships, ed. J. A. Simpson, \& W. S. Rholes. New York: Guilford Press, pp. 46-76, 1998.

[13] M.H. Bornstein, "Children's parents." 55-132. In Ecological settings and processes in developmental systems, ed. Bornstein MH, Leventhal T, vol. 4. Handbook of child psychology and developmental science. Hoboken, NJ: Wiley, 2015.

[14] P.B. Malham, G.Saucier. "The conceptual link between social desirability and cultural normativity." International Journal of Psychology 51(6) (2016): 474480, doi:10.1002/ijop.12261

[15] F.A. Sava. Analiza datelor in cercetarea psibologica [Data analysis in psychological research]. Cluj-Napoca: Editura ASCR, 2011.

[16] F.A. Sava , R.I. Popa. "Personality types based on the Big Five Model. A cluster analysis over the Romanian population." Cognition, Brain, Behavior. An Interdisciplinary Journal 15(3) (2011): 359-384. ASCR Publishing House. 
[17] Buri, J.R.. "Parental authority questionnaire." Journal of Personality Assessment 57 (1991): 110-119. doi:10.1207/s15327752jpa5701_13.

[18] A.M. Diagostin. "Stil parental si depresia la adolescenti” [Parental style and adolescent depression], PhD dissertation, Available on http: //dspace. biblioteca. um.edu.mx/ xmlui/bitstream / handle /20.500.11972/408/Tesis\%20Anca-Mariana \%20 Dragostin. pdf?sequence $=1$ \&isAllowed $=\mathrm{y}$.

[19] R.Fraley , N. Waller \& K.Brennan. "An item response theory analysis of self-report measures of adult attachment." Journal of personality and social psychology 78(2) (2000): 350-365.

[21]Negrei, N., Sava, F.A., "Adaptation of the adult attachment styles inventory for the Romanian population”. Social Psychology 18 (2006): 155169.

[21] H. Masud, , R. Thurasamy, M. S. Ahmad. "Parenting styles and academic achievement of young adolescents: A systematic literature review." Quality and Quantity 49(6) (2015): 2411-2433, available on http://dx.doi.org/10.1007/s11135-014-0120-x 